\title{
Templated, carbothermal reduction synthesis of mesoporous silicon carbide from carbon nanotube-mesoporous silica core-shell composite
}

\author{
JEONGWOOK SEO ${ }^{1, *} \mathbb{D}$, SHRIHARI SANKARASUBRAMANIAN ${ }^{1}$ and BYUNGCHEOL LEE ${ }^{2}$ \\ ${ }^{1}$ Center for Electrochemical Science and Engineering, Department of Chemical and Biological Engineering, Illinois \\ Institute of Technology, Chicago 60616, USA \\ ${ }^{2}$ Quantum Optics Laboratory, Korea Atomic Energy Research Institute, Yuseong-gu 305-353, South Korea \\ *Author for correspondence (jseo16@hawk.iit.edu)
}

MS received 19 October 2016; accepted 9 December 2017; published online 5 February 2018

\begin{abstract}
Mesoporous materials are the subject of extensive interest due to their large surface area and multiscale structural order. These properties are especially relevant for applications such as catalyst supports in both chemical and electrochemical systems. The first part of this study details the synthesis of carbon nanotube-mesoporous silica core-shell composites starting with single-walled carbon nanotubes (SWCNTs) and multi-walled carbon nanotubes (MWCNTs) through micellar selfassembly. The formation of such a composite structure was verified using scanning electron microscopy and further analysis was carried out through X-ray diffraction (XRD). The subsequent refinement of the diffraction pattern revealed the silica shell to be of the continuous cubic ( $I a 3 d$ ) MCM48 structure. The mesoporous silica-carbon nanotube core-shell composite was later subjected to high-temperature carbothermal reduction. Subsequent XRD analysis showed that the reduction product was mesoporous silicon carbide ( $\mathrm{SiC}$ ). Thus, this study details a novel synthesis method for mesoporous $\mathrm{SiC}$, which is an attractive material for possible diverse applications such as catalyst supports, intercalation electrodes and other emerging high technology areas.
\end{abstract}

Keywords. Mesoporous silica; MCM-48; CNT; mesoporous silicon carbide; carbothermal reduction.

\section{Introduction}

Silicon and silica-based materials possessing large surface area with an ordered porous structure offer extensive advantages over bulk amorphous silica or silicon materials in various applications, such as a conventional catalyst support [1], renewable energy production [2] and energy storage systems [3]. A series of ordered mesoporous silica, MCM41s, was first reported by scientists in Mobil in 1992 [4-6], wherein polymerized inorganic precursors were associated with organic surfactants and used to synthesize the mesoporous structure via the 'self-assembly' method. Specifically, the continuous cubic (Ia3d) MCM48 silica was synthesized using a co-surfactant (ethanol, EtOH) or by changing the type of surfactant $[7,8]$. The pore structures of the continuous cubic phase MCM48 and hexagonal phase MCM41 were controlled by the concentrations of the co-surfactant, silica precursor and catalyst [9]. Such ordered mesoporous silica materials assume great technological importance due to their large pore size (3-10 nm), high surface area and narrow pore size distribution. This interest has resulted in extensive research into controlling silica particle shape, and synthesizing nanorods and nanotubes using various type of templates such as polymer fibres [10], porous membranes [11] and nanotube templates [12]. While several studies have reported on various silicon carbide ( $\mathrm{SiC}$ ) morphologies such as spheres [13], 'thorn-ball' spheres [14] and powders [15], this is the first report ever on using carbothermal reduction of a sacrificial carbon nanotube template to generate $\mathrm{SiC}$ nanotubes with a controlled anisotropy.

Silicon and various templated silica materials are promising anode materials for lithium ion cells due to their high theoretical capacity $\left(4200 \mathrm{mAh} \mathrm{g}^{-1}\right)$. However, volumetric expansion during charge and discharge $[16,17]$ causes severe pulverization, cracking and delamination of the electrode, which results in rapid capacity fade. Functional silicon-based materials such as mesoporous silicon sponge [18], nanofibres [3] and nanotubes [19] have been reported to exhibit improved silicon anode capacity. The growing scope of applications requires the exploration of various methods for the production of porous functional silicon from porous silica material through electrochemical reduction, using molten salt [20-22], high temperature carbon reduction [23] and high temperature hydrogen reduction [24], to name a few methods. The surfactant-assisted self-assembly method is of particular interest due to the ability to control the crystal structure through manipulation of the organic template and silica source. This confers the ability to develop and produce various 
type of functional porous silica materials [25-27]. This study details the surfactant-assisted, self-assembly and growth of mesoporous silica (MCM48) on MWCNTs and SWCNTs. Further, this material was subject to high-temperature carbon and hydrogen reduction to produce functional $\mathrm{SiC}$ nanotubes.

\section{Experimental}

Seo et al [9] previously reported the room temperature synthesis of mesoporous silica using the modified Stöber method. Following the procedure outlined above, the typical synthesis involved dissolving $1.7 \mathrm{~g}$ cetyltrimethylammonium bromide (CTABr, Aldrich) surfactant in $37.1 \mathrm{~g}$ ethanol (99.5\%, Junsei Chemical), which acted as the co-surfactant, and adding $0.3 \mathrm{~g}$ of MWCNTs (Iljinnanotech, CVD process, 10-20 nm thickness and 20-30 $\mu \mathrm{m}$ length) to this solution. The resultant mixture was sonicated for $1 \mathrm{~h}$ to achieve uniformity in the distribution of the nanotubes. This was followed by the addition of $32.2 \mathrm{~g} \mathrm{NH}_{4} \mathrm{OH}$ and $42 \mathrm{~g}$ deionized water (aqueous ammonia solution). Finally, $2.5 \mathrm{~g}$ tetraethyl orthosilicate (TEOS, Aldrich) was slowly added drop wise into the solution to serve as the silica source. The mixture was stirred for $4 \mathrm{~h}$ and later kept for $4 \mathrm{~h}$ in static condition. The silica-CNT mixture was filtered after aging to remove unreacted aqueous solution without water washing and dried at $40^{\circ} \mathrm{C}$ for $48 \mathrm{~h}$ with the filtrate containing the desired core-shell composite of mesoporous silica and MWCNTs. Preparation of the core-shell composite of mesoporous silica and SWCNTs (Iljinnanotech, arc-discharge process, $1-1.2 \mathrm{~nm}$ thickness and 5-20 $\mu \mathrm{m}$ ) was carried out using the same process.

The high-temperate carbothermal reduction of mesoporous silica-MWCNT core-shell composite was carried out at 900 and $1100^{\circ} \mathrm{C}$ with $4 \% \mathrm{H}_{2} / \mathrm{N}_{2}$ purge for $20 \mathrm{~h}$ in a zirconia tube furnace. The unreduced core-shell composite was also calcined at $650^{\circ} \mathrm{C}$ in air to remove the organic surfactant and unreacted MWCNT to serve as a comparison to the hightemperature carbothermal reduction products.

The silica-CNT core-shell composite was analysed using a scanning electron microscope (FE-SEM, Hitachi, S-4800) and a transmission electron microscope with facilities for energy dispersive spectroscopy (FE-TEM with EDX, Philips, Tecnai F20) to observe the composite morphology. X-ray diffraction (XRD, SCITAG, XDS 2000) was employed to analyse the mesoporous silica structure with a low $2 \theta(<7$ degree) value. The calcined composite and the high-temperate carbothermal reduction products were also analysed at higher $2 \theta$ values from 10 to 80 degrees.

\section{Results and discussion}

Mesoporous silica, MCM48, was synthesized using the modified Stöber, self-assembly method [9] on MWCNTs and SWCNTs. Figure 1 shows SEM images of mesoporous silica shell over the MWCNT and SWCNT cores. The silica shell was observed to have grown uniformly over the CNT's surface with 100 to $200 \mathrm{~nm}$ shell thickness. The use of MWCNT as the core resulted in the encapsulation of individual MWCNTs by silica, as evident from figure 1a. In contrast, the SWCNT cores were seen to aggregate and bundles of SWCNTs were covered with a silica shell, as shown in figure 1b. The shape of silica growth was observed to be dependent on the dispersion of CNTs in the solution, as depicted in figure 1c. The aggregation of CNTs was expected due to their strong Van der Waals interaction [25] and thus achieving uniform dispersion was recognized to be technically challenging. Figure $1 \mathrm{~d}$ shows evidence of improvement in the dispersion characteristics of the core-shell composite and this was hypothesized to occur due to the silica shell increasing the silica-CNT composite cross-sectional diameter. The silica-CNT composite was later easily dispersed by sonication in ethanol.

The silica shell exhibited layered growth with the shell thickness dependent on the number of silica layers, as evident from figure 1e and $\mathrm{f}$. The first layer that grew out of the CNT surface was found to have a cross-section diameter of $60-100 \mathrm{~nm}$. This was succeeded by a second layer of 150-200 nm cross-sectional diameter. The occurrence of a distinct third layer was found to be a function of the experimental conditions, wherein mixing $0.3 \mathrm{~g}$ of CNT with $2.5 \mathrm{~g}$ TEOS resulted in the absence of the third layer in the SEM analysis. However, a mixture consisting of $0.2 \mathrm{~g}$ of CNT along with 2.5 TEOS resulted in the formation of a third layer with a cross-section diameter of $300 \mathrm{~nm}$, as seen in figure 1f. Thus, this clearly demonstrated that the ratio between CNT and silica source is the key to controlling the thickness of silica layer growth on the CNT.

The observation that the silica core-shell did not cover the tips of the CNTs in the SEM images, depicted in figure 1, is intriguing and can be explained taking CNT surface charge distribution into account [28-35]. The charges on the CNT surface can come from multiple sources including short-range Van der Waal's forces, Coulomb interactions due to partial charges on surface atoms and due to induced charges on the surface [35]. Further, the presence of water molecules (or similar polar species such as low-molecular-weight alcohols) inside a CNT can lead to polarization of the CNT due to interactions with the delocalized $\pi$-electrons [33-35]. $A b$ initio studies by Arab et al [34] showed that even a single $\mathrm{H}_{2} \mathrm{O}$ molecule inside a CNT could significantly polarize the CNT, with the resulting electric field interaction with the $\mathrm{H}_{2} \mathrm{O}$ dipole contributing up to $45 \%$ of the total energy of the system. Other studies report that at the edges of the CNT, the shape of the potential energy curve is dominated by the electrostatic interaction between the point charges on $\mathrm{H}_{2} \mathrm{O}$ and the induced charges on the CNT surface [35]. These simulations point to a change in the charge distribution at the tips of a CNT. We believe that this change in the charge distribution at the tips leads to an inverted arrangement of CTABr surfactant, which repels rather than attracts the TEOS, eventually leading to the silica not being deposited on the surface. 

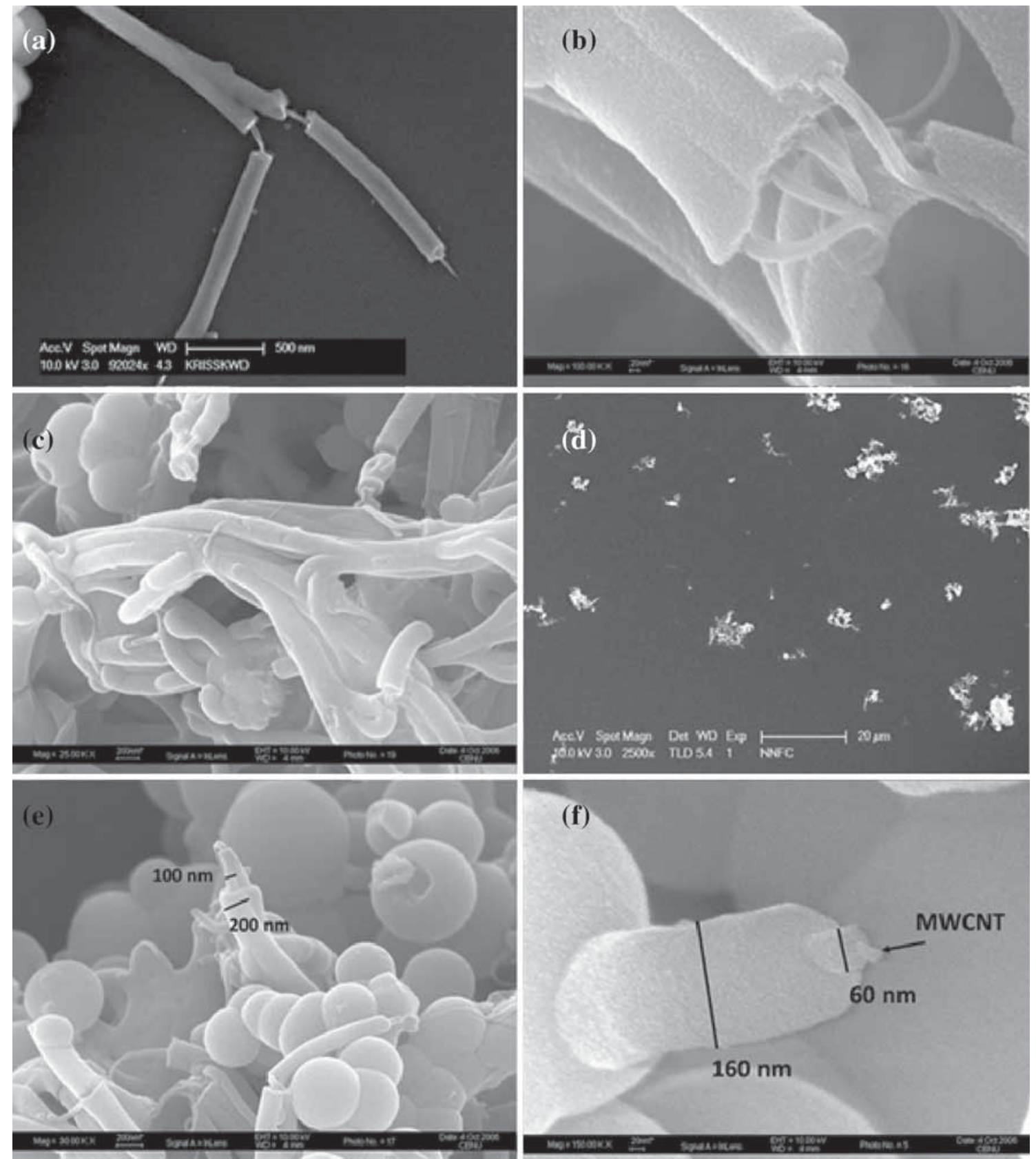

Figure 1. SEM images of mesoporous silica shell on the (a, c, d, e, f) multi-walled carbon nanotube and (b) singlewalled carbon nanotube.

The schematic diagram of the mesoporous silica shell synthesis on the CNT surface through the surfactant-assisted self-assembly method is shown in figure 2 . When surfactant was dissolved into the $\mathrm{EtOH}$, which served as co-surfactant, EtOH associated on the CTABr tail side. This resultant increase in polarity of the CTABr-EtOH composite attracted it to the CNT surface due to its inherent surface polarity [9]. The addition of the silica source (TEOS) along with the $\mathrm{NH}_{4} \mathrm{OH}$ catalyst resulted in $\mathrm{SiO}_{2}$ migrating to the surfactant attached to the CNT surface. Following the initiation of the silica shell growth on the CNT surface, $\mathrm{SiO}_{2}$-surfactant micelles were believed to travel to the surface resulting in the formation of the second silica shell layer with a mesoporous silica structure.

The silica-CNT composite resulting from room temperature synthesis was analysed using TEM and EDX, as shown in figure 3. The hollow structure of MWCNT was clearly observed in the composite. However, observation of the pore structure for this composite was limited under a TEM because of the presence of surfactants in the silica pore and large size 
(a)

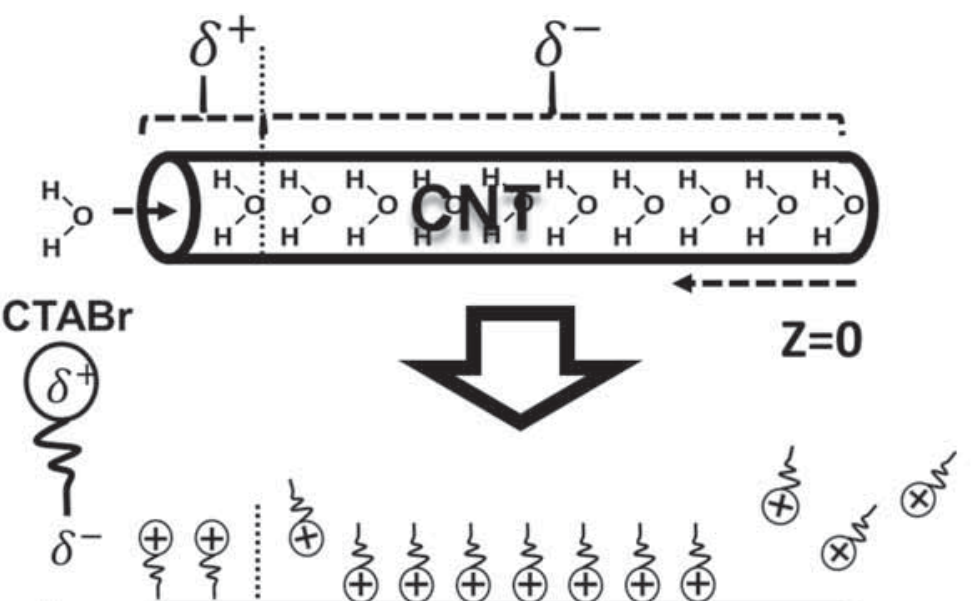

(b)

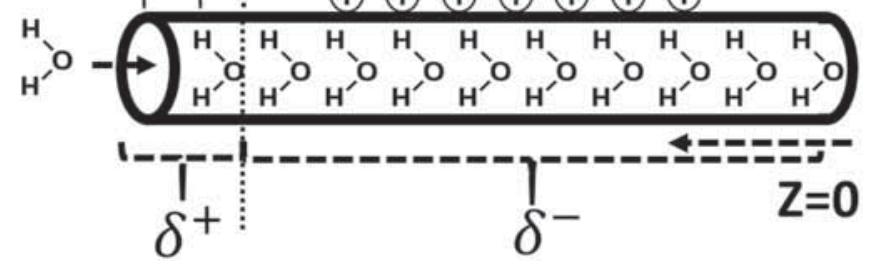

(c)

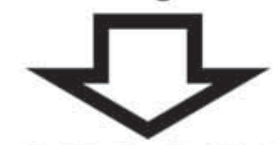

Silica

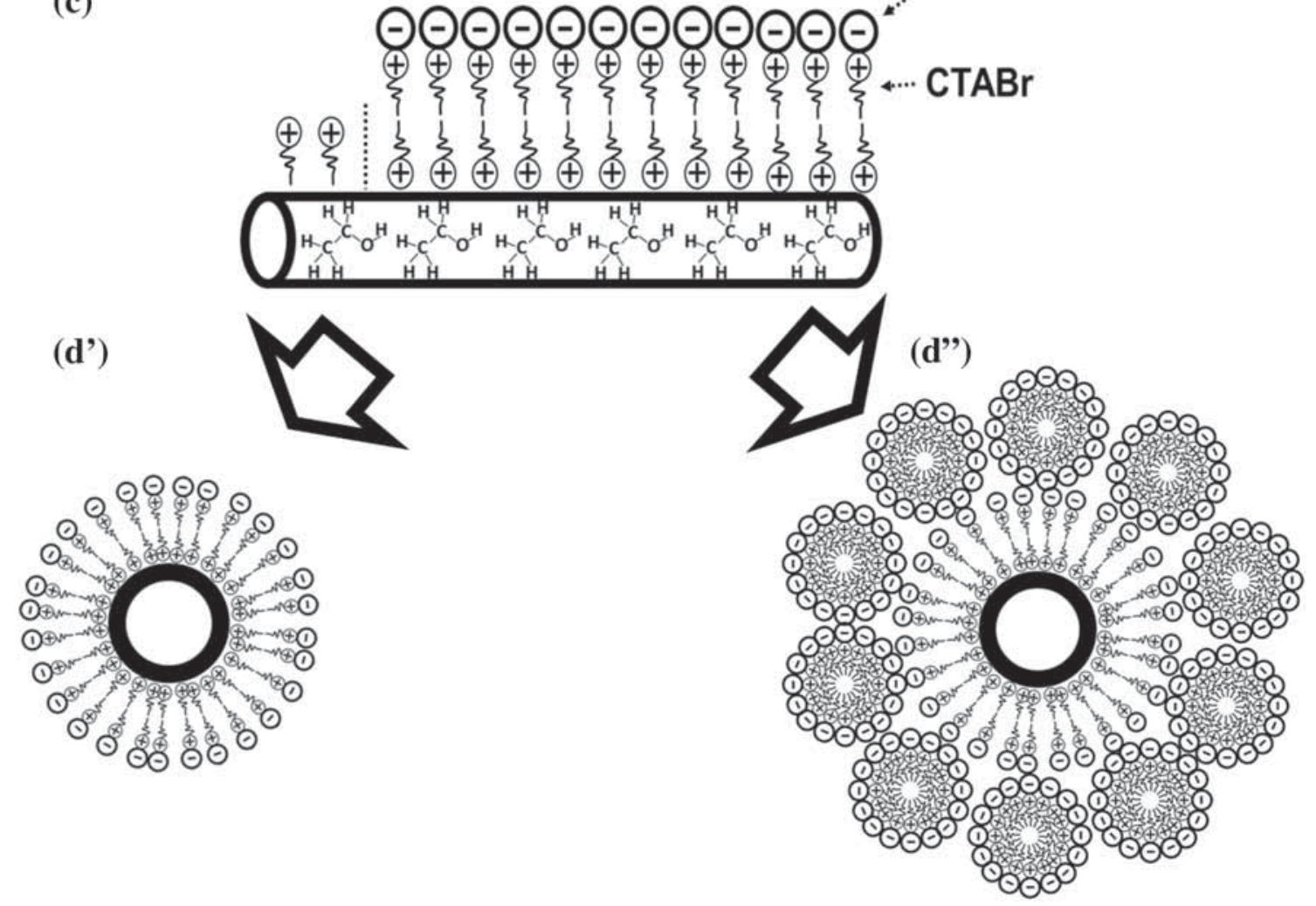

Figure 2. Schematic diagram of mesoporous silica shell synthesis on the CNT surface using self-assembly method.

of the silica shell. The composition of Si on the CNT was confirmed by EDX.

There are a variety of methods reported for the high temperature reduction of $\mathrm{SiO}_{2}$, such as $\mathrm{SiO}_{2}$ powder reduction reaction using hydrogen at $1435^{\circ} \mathrm{C}$ [24], graphitic reduction of $\mathrm{SiO}_{2}$ at temperatures ranging from 1830 to $2200^{\circ} \mathrm{C}$ [23] and $\mathrm{SiO}_{2}$ reduction using graphite with hydrogen gas $\left(5 \% \mathrm{H}_{2} / \mathrm{N}_{2}\right)$ purge at $1450^{\circ} \mathrm{C}$ [36]. This study details the application of 


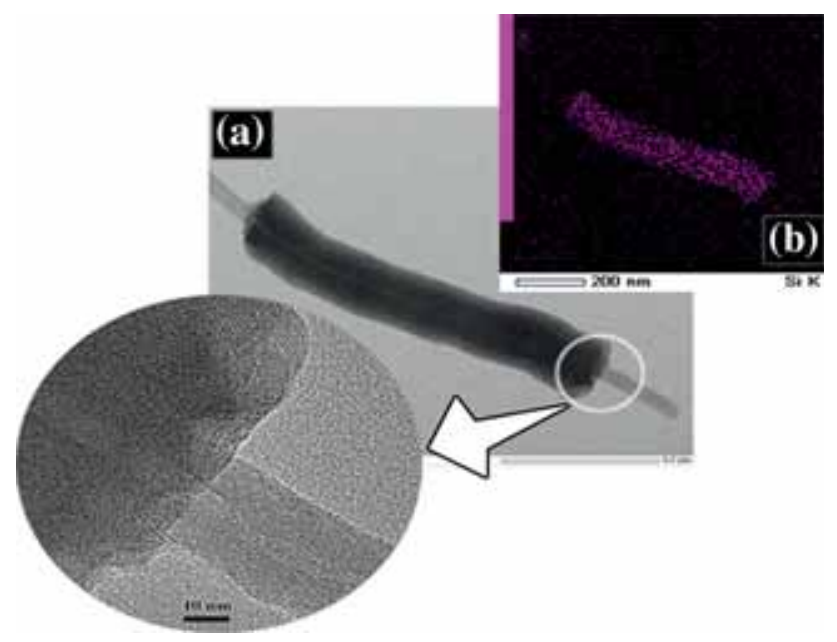

Figure 3. TEM and EDX analysis for the mesoporous silica shell on the MWCNT.

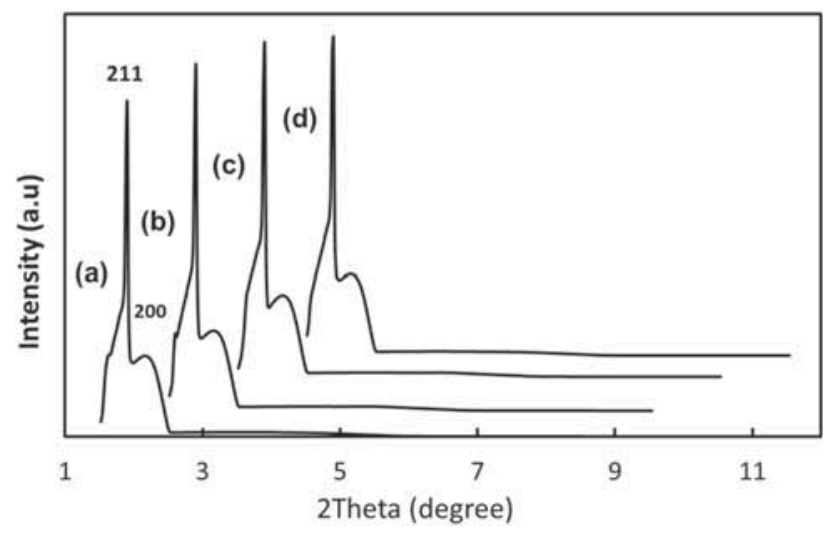

Figure 4. XRD patterns with calcined temperature (a) no heat, (b) $650^{\circ} \mathrm{C}$ in air, (c) $900^{\circ} \mathrm{C}$ in $4 \% \mathrm{H}_{2} / \mathrm{N}_{2}$ and (d) $1100^{\circ} \mathrm{C}$ in $4 \% \mathrm{H}_{2} / \mathrm{N}_{2}$.

high-temperature carbothermal reduction to the CNT-silica core-shell composite. The composite was placed in the zirconia tube furnace and heated to $1100^{\circ} \mathrm{C}$ with a $4 \% \mathrm{H}_{2} / \mathrm{N}_{2}$ gas purge. As explained previously, the addition of TEOS to the CNT-surfactant mixture resulted in the formation of silica-surfactant micelles on the CNT surface, which led to the formation of the silica shell on the CNT. When the carbothermal reduction was carried out with a $4 \% \mathrm{H}_{2} / \mathrm{N}_{2}$ purge, the $\mathrm{SiO}_{2}$ reacted with carbon and hydrogen from the organic surfactant that was a part of the silica-surfactant micelle. This micellar reaction resulted in the lowering of the required reduction temperature to $1100^{\circ} \mathrm{C}$.

The pore structure of the silica shell was analysed using XRD and is shown in figure 4. The XRD pattern was recorded after silica shell was synthesized at room temperature and further refined to confirm the MCM48 structure [9]. Following calcination of the mesoporous CNT-silica core-shell composite at $650^{\circ} \mathrm{C}$ in air and at 900 and $1100^{\circ} \mathrm{C}$ in a mixture of

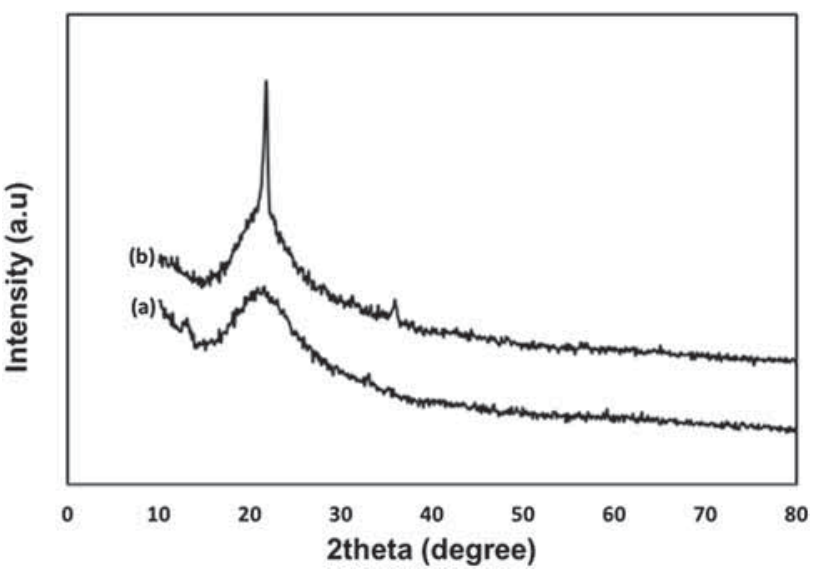

Figure 5. XRD pattern after (a) calcination $650^{\circ} \mathrm{C}$ in air and (b) carbothermal reduction at $1100^{\circ} \mathrm{C}$ in $4 \% \mathrm{H}_{2} / \mathrm{N}_{2}$.

$4 \% \mathrm{H}_{2} / \mathrm{N}_{2}$, the XRD pattern was not observed to change and maintained the typical MCM48 structure.

Figure 5a shows the high $2 \theta$ XRD pattern for the CNTmesoporous silica core-shell composite calcined in air at $650^{\circ} \mathrm{C}$. The low $2 \theta \mathrm{XRD}$ pattern for the product of the high temperature carbothermal reduction of the composite is shown in figure $5 \mathrm{~b}$. When the composite was calcined at $650^{\circ} \mathrm{C}$ in air, all organic surfactants and CNTs were removed and only $\mathrm{SiO}_{2}$ remained as is evident from the XRD pattern. The pattern is seen to be that of typical $\mathrm{SiO}_{2}$ with one large and broad peak between $2 \theta=20$ and 30 . When the composite was treated at $1100^{\circ} \mathrm{C}$ with a $4 \% \mathrm{H}_{2} / \mathrm{N}_{2}$ gas purge, the characteristic $\mathrm{SiC}$ peak near $2 \theta=35$ was observed in the XRD pattern. Compared with the XRD from figures 4 and 5, this supported the account of formation of mesoporous $\mathrm{SiC}$ through high-temperature carbothermal reduction from the mesoporous silica shell-CNT core composite. However, a sharp peak was observed near $2 \theta=22$, in figure 5 , which we hypothesize results from the crystallization of the unreacted $\mathrm{SiO}_{2}$ during the high-temperature carbothermal reaction. The respective reactions in the presence of carbon is shown in the following equation [30]:

$$
\begin{aligned}
\mathrm{SiO}_{2(\mathrm{~s})}+3 \mathrm{C}_{(\mathrm{s})} & =\mathrm{SiC}_{(\mathrm{s})}+2 \mathrm{CO}_{(\mathrm{g})} \\
\Delta \mathrm{G} & =590.0-0.3301 \mathrm{~T}(\mathrm{~kJ})
\end{aligned}
$$

\section{Conclusions}

The mesoporous silica shell was synthesized over MWCNTs and SWCNTs using the modified Stöber, surfactant-assisted self-assembly method at room temperature under basic conditions. Further, the high-temperature carbothermal reduction of the mesoporous silica shell-CNT core composite was carried out and resulted in the production of mesoporous $\mathrm{SiC}$. The mesoporous silica shell resulted in a decrease in the CNT 
Van der Waals interaction and facilitated CNT dispersion. A potential application of the techniques and materials described herein include the dispersion of these core-shell composites followed by the removal of the silica using $\mathrm{NaOH}$ solution to obtain dispersed carbon nanotubes. The electrically insulating property of $\mathrm{SiO}_{2}$ is anticipated to find application as a 'nano-insulation' for CNTs. Finally, the mesoporous SiC composite could find potential application in electrochemical energy storage systems as a high capacity anode.

\section{References}

[1] Park Y K, Yoo M L and Park S H 2014 J. Nanomater. Article ID 596584

[2] Bi C, Zhang H, Zhang Y, Zhu X, Ma Y, Dai H et al 2008 J. Power Sources 184197

[3] Zhou Y, Jiang X, Chen L, Yue J, Xu H, Yang J et al 2014 Electrochim. Acta 127252

[4] Kresge C T, Leonowicz M E, Roth W J, Vartuli J C and Beck J S 1992 Nature 359710

[5] Beck J S, Vartuli J C, Roth W J, Leonowicz M E, Kresge C T, Schmitt K D et al 1992 J. Am. Chem. Soc. 11410834

[6] Pal N and Bhaumik A 2013 Adv. Colloid Interf. Sci. 18921

[7] Kim J M and Ryoo R 1998 Chem. Commun. 2259

[8] Ryoo R, Joo S H and Kim J M 1999 J. Phys. Chem. B 1037435

[9] Seo J W, Lee W J, Nam S, Ryoo H, Kim J N and Ko C H 2015 J. Nanomater. Article ID 149654

[10] Patzsch J and Schneider J J 2013 Dalton Trans. 421451

[11] Zhang A, Hou K, Gu L, Dai C, Liu M, Song C et al 2012 Chem. Mater. 241005

[12] Danumah C, Hemraz U D and Fenniri H 2007 MRS Proc. 1057 II05

[13] Wang K, Wang H and Cheng Y B 2010 Chem. Commun. 46 303

[14] Zheng Y, Zheng Y, Lin L X, Ni J and Wei K M 2006 Scr. Mater. 55883

[15] Guo X, Zhu L, Li W and Yang H 2013 J. Adv. Ceram. 2128
[16] Jerliu B, Huger E, Dorrer L, Seidlhofer B K, Steitz R, Oberst V et al 2014 J. Phys. Chem. C 1189395

[17] Jung S C, Choi J W and Han Y-K 2012 Nano Lett. 125342

[18] Li X, Gu M, Hu S, Kennard R, Yan P, Chen X et al 2014 Nat. Commun. 54105

[19] Park M H, Kim M G, Joo J, Kim K, Kim J, Ahn S et al 2009 J. Nano Lett. 93844

[20] Lin N, Han Y, Zhou J, Zhang K, Xu T, Zhu Y et al 2015 Energy Environ. Sci. 83187

[21] Yang J, Lu S, Kan S, Zhang X and Du J 2009 Chem. Commun. 223273

[22] Cho S K, Fan F F and Bard A J 2012 Electrochim. Acta 6557

[23] Lücke A, Moschen R and Schleser G H 2005 Geochimica et Cosmochimica 61423

[24] Gardner R A 1974 J. Solid State Chem. 9336

[25] Ha T J, Im H G, Yoon S J, Jang H W and Park H H $2011 \mathrm{~J}$. Nanomater. Article ID 326472

[26] Javier G R, Francisco J M R, Carlos A O, Alma G P E and Saúl S V 2013 J. Polymers Article ID 162603

[27] Hu M Z, Shi D and Blom D A 2014 J. Nanomater. Article ID 932160

[28] Girifalco L A, Hodak M and Lee R S 2000 Phys. Rev. 62 13104

[29] Walther J H, Jaffe R, Halicouglu T and Koumoutsakos P 2001 J. Phys. Chem. B 1059980

[30] Keblinski P, Nayak S K, Zapol P and Ajayan P M 2002 Phys. Rev. Lett. 89255503

[31] Du S-P, Zhao W-H and Yuan L-F 2012 Chin. J. Chem. Phys. 25 487

[32] Alexiadis A and Kassinos S 2008 Chem. Rev. 1085014

[33] Thomas J A and McGaughey A J H 2008 J. Chem. Phys. 128 084715

[34] Arab M, Picaud F, Devel M, Ramseyer C and Girardet C 2004 Phys. Rev. B 69165401

[35] Lu D, Li Y, Ravaioli U and Schulten K 2005 J. Phys. Chem. B 10911461

[36] Wan X, Zhang G, Ostrovski O and Aral H 2013 The 13th International Ferroalloys Congress Efficient technologies in ferroalloy industry, June 9-13 